\title{
Pharmacokinetics of prednisolone in children with nephrosis
}

\author{
P F W Miller, C J Bowmer, J Wheeldon, J T Brocklebank
}

\begin{abstract}
The pharmacokinetics of prednisolone given intravenously were studied in 11 children with relapsed steroid responsive nephrotic syndrome, and four control subjects. The clearance of both total and unbound drug was decreased in these children and the unbound fraction of the drug in plasma was significantly correlated with the degree of hypoalbuminaemia. We conclude that changes in the clearance of prednisolone and altered protein binding might account for some of the variability in both therapeutic responses and the incidence of toxicity in patients treated with standard dosage regimens.
\end{abstract}

The introduction of glucocorticoid treatment of steroid responsive nephrotic syndrome reduced the mortality appreciably, but there was still considerable morbidity, with about one third of all patients having at least two relapses within six months of the initial episode. A further third continued to relapse less frequently, while the remainder had no relapses at all. ${ }^{1}$ These differences in outcome have not been explained pathophysiologically, and there is a degree of prognostic variability despite treatment with standardised regimens of glucocorticoid drugs. Insufficient drug treatment might fail to suppress the disease adequately; on the other hand, Leisti and Koskomies found a strong association between severe hypothalamicpituitary-adrenal suppression and a high risk of early relapse. ${ }^{2}$ The degree of hypothalamicpituitary-adrenal suppression is proportional to the dose of glucocorticoid in subjects who do not have nephrotic syndrome so that an excessive dose of glucocorticoids could predispose to early relapse. ${ }^{3}$

The variable prognosis of steroid responsive

Department of Paediatrics and Child Health, St James's

University Hospital,

Leeds

P F W Miller

I F W Mille

J T Brocklebank

Department of

Pharmacology

University of Leeds

C J Bowmer

Correspondence to

Dr P F W Miller,

Macclesfield District

General Hospital,

Victoria Road,

Macclesfield, Cheshire

SK10 3BL.

Accepted 18 September 1989 glucocorticoids in hypoalbuminaemic subjects. The signs of cushingoid toxic effects vary among children with steroid responsive nephrotic syndrome, some patients developing severe occur in steroid responsive $n$ syndrome, and Lewis et al drew attention to the clinical importance of this by showing that there between patients. Glucocorticoids circulate bound to plasma albumin, ${ }^{4}$ transcortin, only the unbound drug is pharmacologically active. ${ }^{4}$ Varying degrees of hypoproteinaemia exprotic syndrome might be explained ticoid drugs. There is considerable potential for complications while others are unaffected despite being given standard doses of prednisolone.

To examine the possibility that the variable prognosis of patients with steroid responsive nephrotic syndrome treated with prednisolone might be associated with changes in the pharmacokinetics of prednisolone, we have studied the kinetics of this drug given intravenously to children with acute nephrosis, using total and unbound plasma concentration times.

\section{Patients and methods}

STUDY DESIGN

Intravenous pharmacokinetic studies were performed on 11 children with relapses of steroid responsive nephrotic syndrome. Their median age was 10 years (range 4-16) and their median plasma albumin concentration was 23 g/l (range: 16-33 g/l) (table 1). Prednisolone was given as an intravenous bolus injection of prednisolone phosphate (Codelsol; Merk, Sharpe and Dohme) 30-64 mg (median: $60 \mathrm{mg}$ ). Ten $3 \mathrm{ml}$ blood samples were taken through an indwelling intravenous cannula at 10, 15, 20, $25,30,60,90,120,240$, and 360 minutes after the injection of prednisolone. Patients were selected for the study because they were expected to be able to tolerate the experimental protocol and in addition, the patients or their parents, or both, had given consent. Ethical approval was given by Leeds Eastern District ethics committee.

Four volunteers aged 14-30 years who did not have nephrosis were also studied after having received a bolus injection of $60 \mathrm{mg}$ of prednisolone. All had normal plasma albumin concentrations between 43-49 $\mathrm{g} / \mathrm{l}$ (table 1 ).

\section{MEASUREMENT OF PLASMA PREDNISOLONE} CONCENTRATIONS

Total prednisolone concentrations were measured by high performance liquid chromatography ${ }^{8}$ using a $30 \mathrm{~cm} \times 3.9 \mathrm{~mm}$ inside diameter stainless steel $10 \mu \mathrm{m}$ porous silica column with a mobile phase consisting of dichloromethane: ethanol:water:glacial acetic acid $(500: 30: 30: 1 \% \mathrm{v} / \mathrm{v})$ at a flow rate of $2 \mathrm{ml} / \mathrm{min}$ and ultraviolet detection at $254 \mathrm{~nm}$. The interassay coefficient of variation was $5 \cdot 3 \%$ $(\mathrm{n}=23)$ at $100 \mathrm{ng} / \mathrm{ml}$ and the limit of detection was $5 \mathrm{ng} / \mathrm{ml}$.

Unbound prednisolone concentrations were measured after ultrafiltration. ${ }^{9}$ A sample of plasma ( $1 \mathrm{ml})$ was placed in a Centrifree ultrafiltration chamber (Amicon) and centrifuged at 
Table 1 Details of children with nephrosis and control subjects

\begin{tabular}{|c|c|c|c|c|c|}
\hline \multirow[t]{2}{*}{ Case No } & \multirow[t]{2}{*}{ Age } & \multirow[t]{2}{*}{ Sex } & \multicolumn{2}{|c|}{ Dose of prednisolone } & \multirow{2}{*}{$\begin{array}{l}\text { Plasma albumin } \\
\text { concentration }(\mathrm{g} / \mathrm{l})\end{array}$} \\
\hline & & & $m g$ & $m g / m^{2}$ & \\
\hline $\begin{array}{l}\text { Children with nephros } \\
1 \\
2 \\
3 \\
4 \\
5 \\
6 \\
7 \\
8 \\
9 \\
10 \\
11\end{array}$ & $\begin{array}{r}13 \\
11 \\
10 \\
16 \\
4 \\
5 \\
11 \\
8 \\
12 \\
9 \\
8\end{array}$ & $\begin{array}{l}\text { Male } \\
\text { Female } \\
\text { Male } \\
\text { Male } \\
\text { Male } \\
\text { Male } \\
\text { Male } \\
\text { Female } \\
\text { Male } \\
\text { Female } \\
\text { Male }\end{array}$ & $\begin{array}{l}65 \\
30 \\
60 \\
60 \\
45 \\
48 \\
64 \\
60 \\
64 \\
60 \\
60\end{array}$ & $\begin{array}{l}42 \cdot 5 \\
28 \cdot 8 \\
61 \cdot 8 \\
37 \cdot 5 \\
67 \cdot 2 \\
60 \cdot 0 \\
44 \cdot 8 \\
61 \cdot 8 \\
50 \cdot 0 \\
46 \cdot 5 \\
65 \cdot 9\end{array}$ & $\begin{array}{l}30 \\
31 \\
18 \\
25 \\
23 \\
28 \\
20 \\
23 \\
16 \\
33 \\
16\end{array}$ \\
\hline $\begin{array}{l}\text { Control subjects: } \\
12 \\
13 \\
14 \\
15\end{array}$ & $\begin{array}{l}30 \\
14 \\
30 \\
30\end{array}$ & $\begin{array}{l}\text { Male } \\
\text { Male } \\
\text { Male } \\
\text { Male }\end{array}$ & $\begin{array}{l}60 \\
60 \\
60 \\
60\end{array}$ & $\begin{array}{l}30 \cdot 7 \\
45 \cdot 5 \\
31 \cdot 2 \\
32 \cdot 8\end{array}$ & $\begin{array}{l}43 \\
45 \\
45 \\
49\end{array}$ \\
\hline $\begin{array}{l}\text { Mean (SD) } \\
\text { for children } \\
\text { with nephrosis } \\
\text { Mean (SD) } \\
\text { for control subjects }\end{array}$ & $\begin{array}{r}9 \cdot 7(3 \cdot 3) \\
26 \cdot 0(6 \cdot 9)\end{array}$ & & $\begin{array}{l}56 \cdot 0(10 \cdot 2) \\
60 \cdot 0(0)\end{array}$ & $\begin{array}{l}51 \cdot 5(12 \cdot 1) \\
35 \cdot 1(6 \cdot 0)\end{array}$ & $\begin{array}{l}23 \cdot 9(5 \cdot 8) \\
45 \cdot 5(2 \cdot 2)\end{array}$ \\
\hline
\end{tabular}

$1500 \mathrm{~g}$ for 25 minutes at $37^{\circ} \mathrm{C}$ in a $35^{\circ}$ fixed angle head. The resultant filtrate was analysed for prednisolone concentration by high performance liquid chromatography.

\section{PHARMACOKINETIC ANALYSIS}

The disappearance of both total and unbound prednisolone from plasma following intravenous injection was initially analysed using the 'C-STRIP' computer programme. ${ }^{10}$ This indicated that the decline of both total and unbound plasma prednisolone concentrations with time was biexponential. Consequently, the intravenous concentration time data was fitted to a biexponential equation $\left(\mathrm{C}=\mathrm{Ae}^{-\alpha \mathrm{t}}+\mathrm{Be}^{-\beta \mathrm{t}}\right)$ using non-linear regression analysis. This procedure gave estimates of $\mathrm{A}$ and $\mathrm{B}$, the intercepts at time zero of the two exponential phases, and $\alpha$ and $\beta$, the respective slopes of each exponential phase. The kinetics of both bound and unbound prednisolone were described in terms of: ( $i)$ the half life $\left(t^{1 / 2}(\beta)\right)$ of the terminal exponential phase of the concentration time data; (ii) the apparent volume of distribution: $\mathrm{V}=\operatorname{dose} / \mathrm{AUC} \beta$ (where AUC is the area under the concentration time curve from time zero to infinity); and (iii) the plasma clearance $(\mathrm{Cl})$. $\mathrm{Cl}=$ dose/AUC. The area under the concentration time curve was calculated from the equation: $\mathrm{AUC}=\mathrm{A} / \alpha+\mathrm{B} / \beta$. To estimate the percentage of prednisolone unbound in plasma during the concentration time profile, an averaged value was calculated. Percentage unbound in plasma $=\mathrm{AUC}_{\mathrm{u}} \times 100 / \mathrm{AUC}_{\mathrm{t}}$, where $A U C_{u}$ and $A U C_{t}$ are the areas under the concentration time curves for the unbound and total drug, respectively.

\section{STATISTICAL ANALYSIS}

Stepwise multiple linear regression analysis was used to discover which variables were related to each pharmacokinetic measurement and to rate these variables in order of their importance. ${ }^{11}$ Pharmacokinetic measurements (area under the concentration time curve, plasma clearance, volume of distribution, and half life $(\beta)$ ) were treated as dependent variables, which were regressed on dose as a function of both surface area and body weight, body weight, surface area, plasma albumin concentration, and age of the subject. Only terms that were significant in the regression equation at the $5 \%$ level were subsequently used.

Results are given as mean (SD) and the significance of differences between groups were assessed by the Mann-Whitney $U$ test. A probability of $<0.05$ was accepted as significant. Clearance and apparent volume of distribution are expressed in terms of body surface area to permit comparisons to be made between children with nephrosis and control subjects.

\section{Results}

Representative profiles of total and unbound prednisolone concentration times after a 60 $\mathrm{mg} / \mathrm{m}^{2}$ intravenous dose of prednisolone are shown in fig 1 . Both curves are characterised by an initial rapid distribution phase $(\alpha)$ followed by a slower elimination phase $(\beta)$ and this pattern was repeated in all subjects studied. Analysis of these data with the 'C-STRIP' programme showed that a biexponential equation was the best fit for each subject studied. The pharmacokinetic measurements of both total and unbound prednisolone in patients with nephrosis and volunteers are shown in tables 2 and 3, respectively, and each pharmacokinetic measurement is discussed below.

AREA UNDER THE CONCENTRATION TIME CURVE AND PLASMA CLEARANCE

Tables 2 and 3 show that there was no difference between area under the concentration time curve for total concentration of the drug for patients with nephrosis and volunteers. Although the area under the concentration curve for the unbound drug was $84 \%$ greater in the group of patients with nephrosis compared 
Figure 1 Disappearance from plasma of total and unbound prednisolone after intravenous administration.
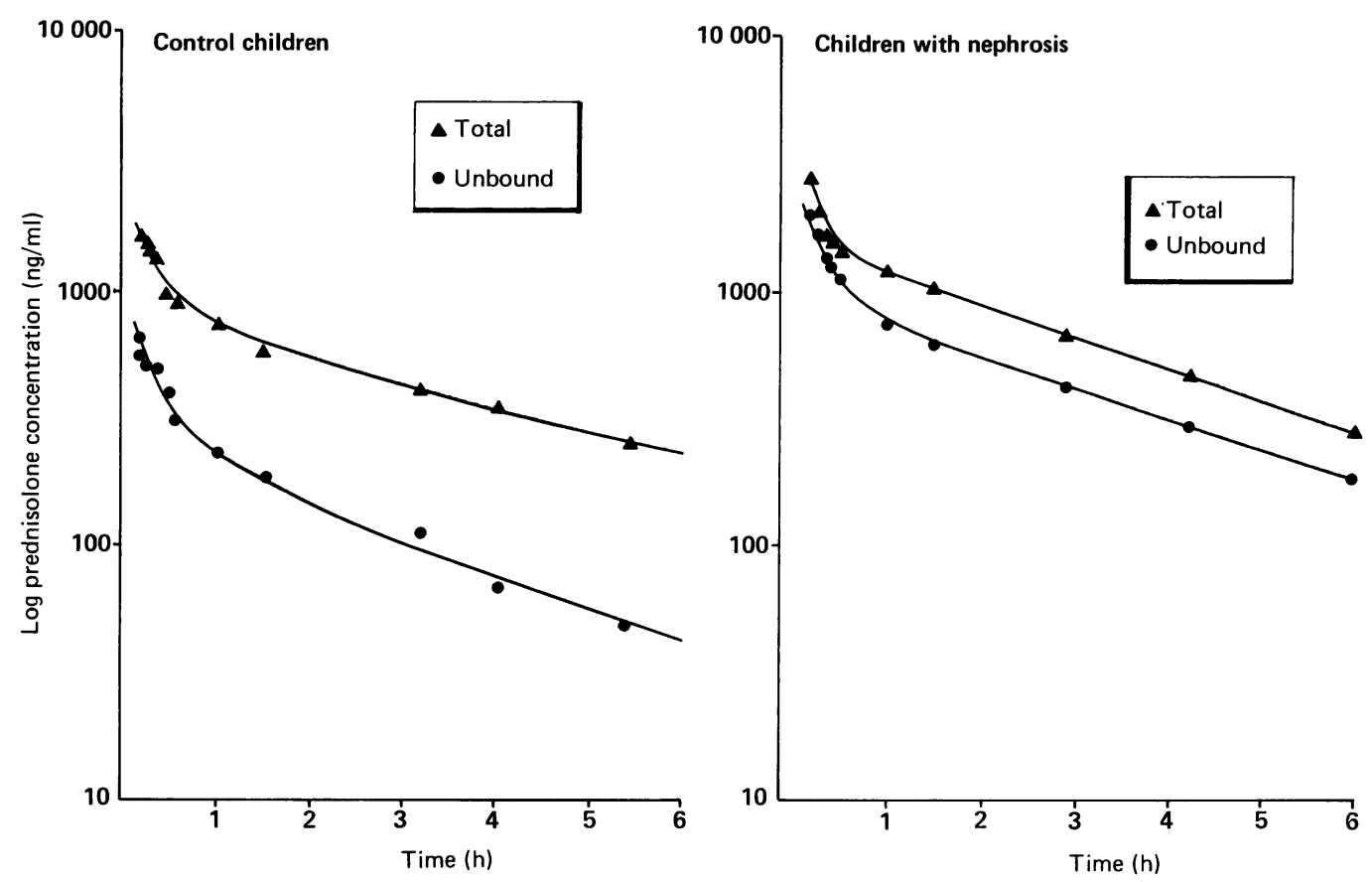

Table 2 Pharmacokinetic measurements calculated from the total and unbound concentration of prednisolone $\left(28 \cdot 8-67 \cdot 2 \mathrm{mg} / \mathrm{m}^{2}\right)$ in children with nephrosis

\begin{tabular}{|c|c|c|c|c|c|c|c|}
\hline Case No & $\begin{array}{l}\text { Area under concentration } \\
\text { time curve for total } \\
\text { concentration of drug } \\
(m g / h / l)\end{array}$ & $\begin{array}{l}\text { Area under concentration } \\
\text { time curve for unbound } \\
\text { concentration of drug } \\
(\text { mg/h/l })\end{array}$ & $\begin{array}{l}\text { Total plasma } \\
\text { clearance } \\
\text { of drug } \\
\left(\mathrm{l} / \mathrm{h} / \mathrm{m}^{2}\right)\end{array}$ & $\begin{array}{l}\text { Plasma clearance } \\
\text { of unbound drug } \\
\left(\mathrm{l} / \mathrm{h} / \mathrm{m}^{2}\right)\end{array}$ & $\begin{array}{l}\text { Total volume } \\
\text { of distribution } \\
\left(\mathrm{ll} \mathrm{m}^{2}\right)\end{array}$ & $\begin{array}{l}\text { Volume of distribution: } \\
\text { of unbound drug } \\
\left(l / \mathrm{m}^{2}\right)\end{array}$ & $\begin{array}{l}\text { Half life } \\
t(\beta) \\
\text { (hours) }\end{array}$ \\
\hline $\begin{array}{r}1 \\
2 \\
3 \\
4 \\
5 \\
6 \\
7 \\
8 \\
9 \\
10 \\
11\end{array}$ & $\begin{array}{l}3 \cdot 8 \\
4 \cdot 2 \\
6 \cdot 2 \\
4 \cdot 1 \\
5 \cdot 6 \\
5 \cdot 0 \\
3 \cdot 6 \\
5 \cdot 5 \\
5 \cdot 4 \\
3 \cdot 6 \\
5 \cdot 2\end{array}$ & $\begin{array}{l}1 \cdot 7 \\
1 \cdot 0 \\
4 \cdot 0 \\
2 \cdot 0 \\
3 \cdot 2 \\
2 \cdot 4 \\
2 \cdot 1 \\
3 \cdot 6 \\
3 \cdot 4 \\
1 \cdot 1 \\
2 \cdot 6\end{array}$ & $\begin{array}{l}3 \cdot 1 \\
1.9 \\
2 \cdot 8 \\
2 \cdot 6 \\
3 \cdot 4 \\
3 \cdot 3 \\
3 \cdot 4 \\
3 \cdot 1 \\
2 \cdot 6 \\
4 \cdot 7 \\
3 \cdot 2\end{array}$ & $\begin{array}{r}7 \cdot 0 \\
7 \cdot 9 \\
4 \cdot 3 \\
5 \cdot 2 \\
5 \cdot 9 \\
7 \cdot 1 \\
6 \cdot 0 \\
4 \cdot 8 \\
4 \cdot 2 \\
15 \cdot 1 \\
6 \cdot 5\end{array}$ & $\begin{array}{l}44 \cdot 4 \\
28 \cdot 0 \\
35 \cdot 1 \\
31 \cdot 3 \\
24 \cdot 2 \\
22 \cdot 5 \\
30 \cdot 7 \\
25 \cdot 8 \\
25 \cdot 0 \\
42 \cdot 1 \\
16 \cdot 5\end{array}$ & $\begin{array}{l}73 \cdot 8 \\
41 \cdot 1 \\
57 \cdot 7 \\
42 \cdot 5 \\
43 \cdot 9 \\
55 \cdot 0 \\
65 \cdot 0 \\
29 \cdot 8 \\
35 \cdot 1 \\
65 \cdot 1 \\
48 \cdot 4\end{array}$ & $\begin{array}{l}2 \cdot 7 \\
2.9 \\
2 \cdot 4 \\
2.4 \\
1.4 \\
1.3 \\
1.8 \\
1.9 \\
1.9 \\
2.0 \\
2.2\end{array}$ \\
\hline Mean (SD) & $4 \cdot 7(0.9)$ & $2 \cdot 5^{*}(1 \cdot 0)$ & $3 \cdot 1(0 \cdot 7)$ & $6 \cdot 7^{* *}(2 \cdot 9)$ & $29 \cdot 6(8 \cdot 0)$ & $50 \cdot 7^{*}(13 \cdot 8)$ & $2 \cdot 1(0.5)$ \\
\hline
\end{tabular}

${ }^{*} \mathrm{p}>0.01 ;{ }^{* *} \mathrm{p}>0.001$ compared with value calculated for total prednisolone.

Table 3 Pharmacokinetic measurements calculated from the total and unbound plasma concentrations of prednisolone (30 $7-45 \cdot 5 \mathrm{mg} / \mathrm{m}^{2}$ given intravenously) in control subjects

\begin{tabular}{|c|c|c|c|c|c|c|c|}
\hline Case No & $\begin{array}{l}\text { Area under concentration } \\
\text { time curve for total } \\
\text { concentration of drug } \\
(\mathrm{mg} / \mathrm{h} / \mathrm{l})\end{array}$ & $\begin{array}{l}\text { Area under concentration } \\
\text { time curve for unbound } \\
\text { concentration of drug } \\
(\mathrm{mg} / \mathrm{h} / \mathrm{l})\end{array}$ & $\begin{array}{l}\text { Total plasma } \\
\text { clearance } \\
\text { of drug } \\
\left(\mathrm{l} / \mathrm{h} / \mathrm{m}^{2}\right)\end{array}$ & $\begin{array}{l}\text { Plasma clearance } \\
\text { of unbound drug } \\
\left(\mathrm{l} / \mathrm{h} / \mathrm{m}^{2}\right)\end{array}$ & $\begin{array}{l}\text { Total volume } \\
\text { of distribution } \\
\left(\mathrm{l} / \mathrm{m}^{2}\right)\end{array}$ & $\begin{array}{l}\text { Volume of distribution: } \\
\text { of unbound drug } \\
\left(\mathrm{l} / \mathrm{m}^{2}\right)\end{array}$ & $\begin{array}{l}\text { Half life } \\
t^{\prime}(\beta) \\
\text { (hours) }\end{array}$ \\
\hline $\begin{array}{l}12 \\
13 \\
14 \\
15\end{array}$ & $\begin{array}{l}4 \cdot 4 \\
4 \cdot 2 \\
3 \cdot 7 \\
3 \cdot 4\end{array}$ & $\begin{array}{l}1 \cdot 1 \\
1 \cdot 5 \\
1 \cdot 4 \\
1 \cdot 3\end{array}$ & $\begin{array}{r}7 \cdot 4 \\
10 \cdot 7 \\
8 \cdot 9 \\
9 \cdot 6\end{array}$ & $\begin{array}{l}30 \cdot 3 \\
29 \cdot 7 \\
23 \cdot 3 \\
24 \cdot 5\end{array}$ & $\begin{array}{l}41 \cdot 0 \\
28 \cdot 8 \\
26 \cdot 5 \\
28 \cdot 6\end{array}$ & $\begin{array}{r}107 \cdot 0 \\
50 \cdot 8 \\
63 \cdot 2 \\
103 \cdot 0\end{array}$ & $\begin{array}{l}3 \cdot 8 \\
2 \cdot 7 \\
2 \cdot 1 \\
2 \cdot 1\end{array}$ \\
\hline Mean (SD) & $3.9(0.5)$ & $1 \cdot 3^{* *}(0 \cdot 2)$ & $9 \cdot 1 \dagger(1 \cdot 4)$ & $27 \cdot 0^{* * *} \dagger(3 \cdot 6)$ & $31 \cdot 2(6 \cdot 6)$ & $81 \cdot 0^{*}(28 \cdot 2)$ & $2 \cdot 7(0 \cdot 8)$ \\
\hline
\end{tabular}

${ }^{*} \mathrm{p}<0.01 ;{ }^{* *} \mathrm{p}<0.001$ compared with value calculated for total prednisolone; $+\mathrm{p}<0.01$ compared with total plasma clearance and plasma clearance of unbound drug for children with nephrosis (table 2).

with the volunteers, this increase was not significant. Both total plasma clearance and plasma clearance of the unbound drug were, however, significantly less $(\mathrm{p}<0.01)$ than their corresponding mean values in the volunteers (tables 2 and 3). Multiple linear regression analysis did not find any variables that correlated with total plasma clearance in patients with nephrosis, but clearance of the unbound drug was significantly related to plasma albumin concentration $(\mathrm{r}=0.69, \mathrm{p}<0.05)$ (fig 2).

\section{APPARENT VOLUME OF DISTRIBUTION}

Total volume of distribution was similar in the two groups when corrected for body size, but the volume of distribution of the unbound drug in the patients with nephrosis was $37 \%$ less than 
Figure 2 Percentage fraction of unbound prednisolone and plasma albumin concentration in children with nephrosis.

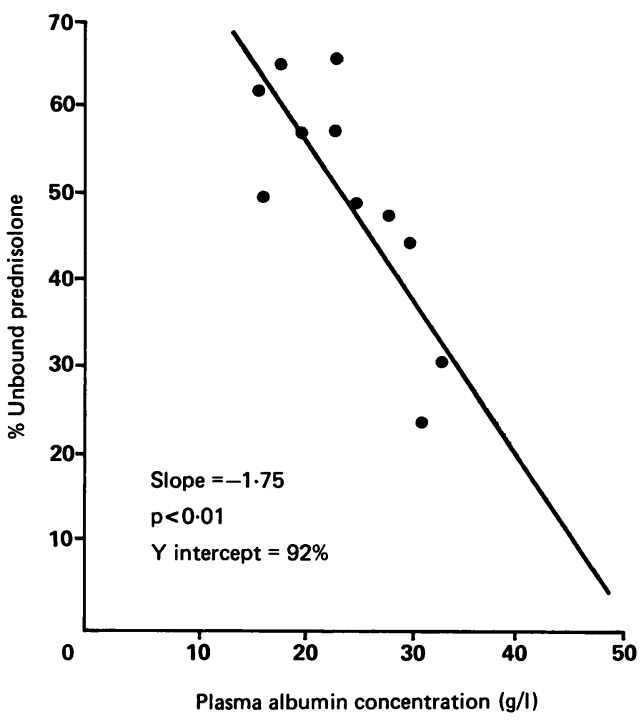

the mean value for the volunteers (tables 2 and 3). There was, however, no significant difference between the two groups. In patients with nephrosis both total volume of distribution and volume of distribution of the unbound drug were significantly correlated with body weight $(\mathrm{p}<0.001)$

\section{HALF LIFE OF PREDNISOLONE}

The half life of prednisolone in both groups is shown in tables 2 and 3, respectively; there was no difference between the two study groups. The dose of prednisolone $/ \mathrm{kg}$ body weight was the only variable to be significantly correlated with half life in patients with nephrosis $(\mathrm{r}=0.68 ; \mathrm{p}<0.05)$. It is unlikely, however, that this correlation is of importance because neither total plasma clearance nor total volume of distribution were dependent on the dose of drug given.

\section{PERCENTAGE OF UNBOUND PREDNISOLONE}

In patients with nephrosis the mean of the concentration averaged value of the percent of drug unbound was $50(13) \%(n=11)$, and in volunteers it was $30(7 \cdot 0) \%(n=4)$, though this difference was not significant.

The variation in percentage of unbound prednisolone and its correlation with plasma albumin concentration in patients with a relapse of nephrosis is shown in fig 2. As expected the relationship between these two variables was inverse $(r=-0.78 ; p<0.01)$, which suggests that as plasma albumin concentrations decrease, there is a concomitant increase in the fraction of unbound prednisolone. The intercept at zero albumin concentration, gives a value for percentage of unbound prednisolone of about $92 \%$, which suggests that the bulk of prednisolone is bound to albumin in the range of doses tested in this study. There was no significant correlation between the percentage of unbound prednisolone and total volume of distribution, volume of distribution of unbound drug, half life, and total clearance of the drug. There was, however, an inverse correlation between the percentage of unbound predinsolone and the clearance of unbound prednisolone $(\mathrm{r}=-0.74 ; \mathrm{p}<0.001)$.

\section{Discussion}

We found a mean half life of $2 \cdot 1(0.5)$ hours in both groups which is in agreement with other studies that have reported 1.4 to 3.5 hours. ${ }^{12}$ The half life of prednisolone in children with nephrosis was not significantly different from that in the controls. In contrast, the clearance of both total and unbound drug was less in the children with nephrosis than in the controls. This emphasises the importance of not using half life alone to describe elimination, as this measurement is also influenced by the apparent volume of distribution. The volumes of distribution of total and unbound drug tended to be lower in patients with nephrosis, and this probably accounts for the lack of any difference in half life between the two groups. The reason for the reduced clearance of prednisolone in the patients is not clear, but it may be related to the difference in age between the patients and volunteers, or it may be that the elimination of prednisolone is impaired in children with nephrosis.

In this study we found a significant inverse correlation between the concentration averaged percentage of unbound prednisolone, and the plasma albumin concentration in children with nephrosis. A similar association between the proportion of drug in the unbound form and plasma albumin concentration has previously been shown in individual plasma samples as opposed to the complete concentration time that we used. ${ }^{13} 14$

Interestingly total clearance of prednisolone was not correlated with either the plasma albumin concentration or percentage of unbound prednisolone. This suggests either that total clearance of the drug is not dependent on the fraction of unbound drug, or that the clearance of unbound prednisolone decreases as the percentage of unbound prednisolone increases. The latter explanation seems more likely, because a significant inverse relationship was found between the percentage of unbound prednisolone and the plasma clearance of the unbound drug in children with nephrosis. Total clearance would not change, because this measurement is related to the unbound fraction and clearance of the unbound drug through the relationship: total clearance equals the unbound fraction multiplied by the clearance of the unbound drug. Thus if the percentage of unbound prednisolone increased and clearance of the unbound drug decreased in proportion, no change would be expected in total clearance.

Prednisolone is largely cleared by the liver and the plasma clearance of unbound drug is a measure of the intrinsic clearance by this organ. Intrinsic clearance is dependent on the metabolic activity of the liver and as clearance of the unbound drug decreases with increasing severity of hypoalbuminaemia, it seems likely that the ability of the liver to eliminate prednisolone is impaired in children with active nephrosis. Liver function may be deranged in 
nephrotic syndrome as shown by the disturbance in the regulation of plasma lipids and its apparently limited ability to synthesise plasma albumin.

What is the clinical relevance of the reduction of clearance of the unbound drug and the increase in the percentage of prednisolone that is unbound in children with nephrosis? Both these changes are likely to make more unbound active drug available to target tissues. Leisti and Koskomies showed that patients who developed severe hypothalamic pituitary adrenal suppression after treatment with prednisolone are likely to relapse in the first year. ${ }^{2}$ Furthermore there is a direct association between the dose of prednisolone given and the degree of hypothalamic pituitary adrenal suppression in subjects who do not have nephrosis, and so increased availability of unbound prednisolone would be expected to cause a high degree of hypothalamic pituitary adrenal suppression thereby increasing the chances of developing frequent relapses of the disease. ${ }^{3}$ Leisti and Koskomies emphasised the importance of minimising prednisolone dosage to avoid causing suppression of the hypothalamic pituitary adrenal axis. The better progression of a group of children whose prednisolone was gradually tapered down compared with a more sudden cessation may be because the hypothalamic pituitary adrenal axis was allowed to recover in the former group. ${ }^{15}$ Simply reducing the duration of treatment with prednisolone is too crude an approach, as shown in a recent study. ${ }^{16}$ It is likely therefore that tailoring the dose of prednisolone to an individual patient's requirements by relating it to plasma albumin concentration and to hypothalamic pituitary adrenal suppression will be the most successful approach to reducing the number of further relapses of nephrosis.

Lewis et al showed that there was an increased risk of glucocorticoid toxicity in hypoalbuminaemic patients, and suggested that this was the result of increased availability of glucocorticoids through decreased protein binding. ${ }^{7}$ It is notable that nephrotic children receiving similar doses of prednisolone show variable degrees of toxicity, which again may be mediated through variable clearance and protein binding.

Rane and Wilson suggested that paediatric doses should be calculated using surface area because this variable correlates with several physiological factors influencing drug disposition. ${ }^{17}$ In this study the dose of prednisolone/kg body weight was more closely correlated with pharmacokinetic measurements than dose/unit surface area. Prednisolone is prescribed for children with nephrosis by some paediatricians using body weight, and by others using surface area; we advocate the former.

In conclusion, the results of this study suggest that decreased plasma clearance of total and unbound prednisolone, together with variable protein binding, are important factors in determining the exposure of tissues to the pharmacologically active form of prednisolone in children with nephrosis. Furthermore in these patients the clearance of unbound prednisolone decreases with the severity of hypoalbuminaemia. Thus it might be advisable to reduce the dosage in accordance with albumin concentration. Additional work is required to characterise fully the disposition of prednisolone in children with active nephrosis, particularly when it is given orally and to assess the implications of the observations reported here for the clinical use of prednisolone.

1 Report of the International Study of Kidney Disease in Children. Early identification of frequent relapsers amon children with minimal change nephrotic syndrome. 7 Pediatr 1982;101:514-8.

2 Leisti S, Koskomies O. Risk of relapse in steroid-sensitive nephrotic syndrome, effect of stage of post prednisolone adrenocortical suppression. $\mathcal{F}$ Pediatr 1983;163:553-7.

3 Livanou T, Ferriman D, James V. Recovery of hypothalmic pituitary function after corticosteroid therapy. Lance 1974;ii:910-2.

4 Steele WH, Hawksworth GM, Barber HE. The binding of prednisolone in human serum and to recrystallised human
albumin in vitro. $\mathrm{Br} \mathcal{F}$ Clin Pharmacol 1982;14:667-77.

5 Slaynwhite WR, Lockie GN, Back NN, Snadberg AA Inactivity in vitro of transcortin bound cortisol. Science 1962;135:1062-3.

6 Milsap RL, Jusko WJ. Binding of prednisolone to, acid glycoprotein. I Steroid Biochem 1983;18:191-4.

7 Lewis GP, Jusko WJ, Burke CW, Graves L. Prednisolone side effects and serum protein levels. Lancet 1971;ii: 778-80.

8 Hartley R, Brocklebank JT. Determination of prednisolone in plasma by high performance liquid chromatography. Chromatogr 1982;232:406-12.

9 Miller PFW, Wheeldon J, Brocklebank JT. The separation of unbound prednisolone in plasma by centrifugal ultrafiltration. I Pharm Pharmacol 1987;39:939-41.

10 Sedman AJ, Wagner JG. 'C Strip' a Fortran III program for obtaining initial polyexponential parameter estimates. f Pharm Sci 1976;65:1006-10.

11 Nie H, Hull CH, Jenkins JG, Steinbrenner K, Bent DH. Statistical package for the social sciences. London: McGraw Hill, 1975 .

12 Green OC, Winter RJ, Kawahara FS, et al. Pharmacokinetic studies of prednisolone in children. $\mathcal{f}$ Pediatr 1978;93:299-303.

13 Rocci ML, Assael BM, Appiani AC, Edefonti A Jusko WJ. Effect on nephrotic syndrome on absorption and disposition of prednisolone in children. Int $\mathcal{F}$ Pediat and disposition of pred

14 Gatti G, Perucca E, Friggo GM, Notarngelo L, Barberis L, Martini A. Pharmacokinetics of prednisolone and its metabolite prednisone in children with nephrotic syndrome during the active place and in remission. $\mathrm{Br} \mathcal{F}$ Clin Pharmacol 1984;17:423-31.

15 Ueda N, Chihara M, Kawaguchi S, et al. Intermittent versus long term tapering prednisolone for initial therapy in children with idiopathic nephrotic syndrome. 7 Pediat 1988;112:122-6.

16 Arbeitgemeinschaft Fur Padiatrische Nephrologie. Short versus standard prednisolone therapy for initial treatment of idiopathic nephrotic syndrome in children. Lancet 1988;i:380-3.

17 Rane A, Wilson JT. Clinical pharmacokinetics in infants and children. Clin Pharmacokinet 1976;1:2-24. 